economic and social developments in the Caribbean, and to prepare the way for publications and other teaching material.

The University College of the West Indies faces many problems, such as its need for further funds and endowments and the task of building up its library resources at a time of famine in books; but the speed and efficiency with which it has developed in its first two years augur well for its further progress. $21 / 3$

\section{BUILDING RESEARCH IN GREAT BRITAIN}

THE work carried ou at the Building Research Station undefth firection of the Building Research Board Nvell Nown to all those interested in the design and construction of civil engineering works of eve the first lephrt of the Board* after the interruption caulg d the War is very welcome.

Thd report covers the period 1940-45, and is divided into two parts, the first of which deals with the normal programme of research in progress in 1945. The second gives an account of the work carried out at the Building Research Station during the War, but contains much information capable of more general application. Finally, there is a classified list of technical publications by the Board and by members of the staff of the Station, which provides a useful guide to current literature. The field covered by the report is very wide, and the space devoted to each aspect of research is necessarily brief; but enough information is given to make clear the method of research and the results obtained.

The first section of the main body of the report deals with investigations into structural materials. The Station has collaborated in a technical survey of the brick-making industry, the testing programme for which was completed in 1945. Work on cement and concrete has dealt with the suitability of different types of limestone aggregates for roads, and with various light-weight concretes. Methods of steam curing have also been studied, and a programme of tests has been carried out at a factory making precast concrete products, to examine the degree of control of quality attainable. Methods which have been developed for determining the specific surface of cements by measurement of air permeability or by nitrogen absorption are likely to be applicable to many other fine powders, and have already been used for some industrial materials.

Perhaps the most generally interesting part of the Station's work is that dealing with the design of domestic buildings. Here the investigation falls into two parts, the first dealing with structural tests on non-traditional methods of construction, and the second with heat insulation, lighting, plumbing and ventilation. The experimental work was carried out on complete houses built for the purpose on land adjacent to the Station. These were then let to tenants whose daily experiences will provide a check on the conclusions reached experimentally. This work is to be continued and extended. Before leaving the subject of house construction, mention must be made of the committees set up by the Ministry of

* Department of Scientific and Industrial Research. Report of the Building Research Board, with a Report of the Director of Building Research for the Years 1940-1945. Pp. viii +112. (London: H.M. Stationery Office, 1948.) 38. 6d. net.
Works to study various aspects of post-war building. The Station was responsible for five of these committees, and provided assistance to others.

Another major investigation is that which started in conjunction with the Ministry of War Transport into the behaviour under load of composite bridge deck systems. The approach to this problem is of interest as indicating the systematic methods adopted by the Station when dealing with complex practical problems. The mathematical analysis is complicated and lengthy, and a series of full-scale tests to cover the whole field is obviously impracticable. The analysis will therefore be accompanied by a number of tests on small models, and the results from these will be compared with those obtained from a few larger models and from actual bridges, thus indicating whether any special conditions of restraint which occur in actual structures have been left out of consideration in the laboratory tests.

Other tests made on existing bridges to determine their suitability for the heavy traffic of war-time showed that many old bridges could safely carry a load of two or three times their 'safe load' as estimated by the usual methods. It was also found that in no case did the dynamic stress caused by a travelling load exceed by more than 30 per cent that produced by the same load at rest.

In connexion with these and other tests, much work has been done on the development and use of the acoustic strain-gauge and the wire-resistance strain-gauge. The acoustic gauge has been found to be particularly valuable both for field and laboratory work, and a method of measuring dynamic strains with it has been worked out. The description of the mobile instrument laboratory is of interest.

Work on soil mechanics has been directed mainly towards the general problem of house foundations. In particular, the cracking and settlement of dwelling houses on clay has been studied, and types of foundation design have been evolved which should prevent this trouble. A point of interest is the discovery that fast-growing trees, such as poplars and elms, may cause serious cracking at distances of as much as $50 \mathrm{ft}$., owing to the withdrawal of water by their roots.

Studies have also been made of the soil conditions on the sites of several large new civil engineering works. One of the most interesting is the comprehensive investigation carried out in connexion with the proposed Flood Protection Scheme in the Fenland.

The war-time work of the Station ranged from the examination of possible substitutes for scarce materials, such as the use of synthetic bauxite in the manufacture of aluminous cement, to model tests of the effect on structures of explosions in earth, air and water. One of the most spectacular was the destruction of the $1 / 20$-scale model of the Mohne Dam. The success of the air attack made in 1943 upon the actual dam is well known.

A war-time development which will be of permanent value was the establishment of a sound basis for the design of reinforced concrete railway-sleepers. Measurements were made of the load transmitted to the sleeper during the passage of the train, using a robust and compact weighing-device, which, after removal of a chair, could be placed between the rail and sleeper without disturbing the foundation of the tracks. The distribution of pressure under the sleeper was measured by placing between it and the ballast a 'ball sandwich', composed of two steel plates between which were 150 or more hardened steel balls. 
By measuring the indentations made by these, the load distribution could be determined.

The risk of fire is present both in peace and war, and has been studied by the Station from several points of view. The effect of heat on the strength of concrete and other structural materials has been examined. Tests have been developed to evaluate the degree to which different wall-coverings contribute to or retard the rapid spread of fire. The principles of lay-out to prevent the spread of fire by radiation between buildings have been worked out.

It has only been possible to refer to the more important items discussed in the report; but it will be seen that the range covered includes something of interest to anyone concerned with civil engineering construction. It is satisfactory to learn from the introductory report of the Board that the importance of the Station's work has been recognized by the recruitment of additional staff and the provision of further facilities for research.

\section{MOON ECHOES AND PENETRA- TION OF THE IONOSPHERE}

\author{
BY F. J. KERR, C. A. SHAIN \\ AND
}

\section{C. . HIGGINS}

Division of Radiophysics, Council for Scientific and Indusfrial Research, Australia

$\mathbf{N}$ ORMAL idnospheric sounding technique can provide juformation on only the lower portion of the $F$-reglon, since waves capable of reaching beyond the level of maximum ionization are not returned to earth by any processes occurring within the ionog phere itself.

The eception of solar and cosmic radio noise at the exth's surface demonstrates that radio energy of shfficiently high froquency can penetrate the ionosphere, but unexpected ionospheric effects are sometimes found in records of $60 \mathrm{Mc} / \mathrm{s}$. solar noise near sunrise. For a study of transmission right through the ionosphere, a signal from a controlled source is to be preferred to the highly variable emissions from the sun. It was thought that signals reflected from the moon might be used in this way for investigation of the ionosphere, and a series of exploratory tests was therefore undertaken.

Moon echoes were first obtained by the U.S. Army Signal Corps ${ }^{1}$ and by Bay $^{2}$ early in 1946, in the metre wava-length region. The American observers reported large amplitude variations, which may have been due to ionospheric effects. For a specific study of the ionosphere it is desirable to work at lower frequencies, and it has been possible to use facilities already available in Australia for preliminary tests at these frequencies.

The results obtained to date may be summarized briefly as follow :

(1) Echoes from the moon have been obtained on thirteen out of fifteen attempts.

(2) The amplitude of the echoes was sometimes of the order expected on theoretical grounds, but more commonly it was considerably less.

(3) As the moon rose, echoes could not be obtained. until the moon's angle of elevation was higher than was expected from calculations based on vertical. incidence ionospheric soundings.
(4) Analysis of $20 \mathrm{Mc} / \mathrm{s}$. solar noise also shows ionospheric effects, with the significant difference that solar noise energy has been received at lower eleva. tions of the sun than expected.

\section{Experimental Arrangements}

On several days each month, the moon passes through aerial beams used by the high-frequency broadcasting station Radio Australia for regular transmissions to the United States and Canada. This station is located in Shepparton, Victoria. With the co-operation of the Postmaster-General's Department, arrangements have been made for the use of a transmitter at this station when it is not required for broadcasting. The transmitter is pulsed by landline from the Radiophysics Laboratory receiving station at Hornsby, New South Wales, 380 miles away. The electrical characteristics of the system used in the preliminary tests are summarized below.

Transmitter : VLC $9,17.84 \mathrm{Mc} / \mathrm{s} ., 50 \mathrm{~kW}$. output, or $V L B 5,21.54 \mathrm{Mc} / \mathrm{s} ., 70 \mathrm{~kW}$. output.

Receiver: R.C.A. type $A R 88$ communications receiver, with the band-width adjusted to $70 \mathrm{c} / \mathrm{s}$. The stability with regulated supplies was such that slight retuning was necessary every 10-15 min.

Transmitting aerial: 16-element broadside array, with maximum of beam at $63^{\circ}$ azimuth, $9^{\circ}$ elevation, and first minimum in vertical plane at $23 \frac{1}{2}^{\circ}$. Gain over an isotropic radiator, $22 \mathrm{db}$.

Receiving aerial: Rhombic aerial system, directed towards the region of the sky illuminated by the transmitting aerial. Beam steerable over a limited sector in the horizontal plane. Calculated gain over an isotropic radiator is $17 \mathrm{db}$. at $17.84 \mathrm{Mc} / \mathrm{s}$.

Display: (a) Long-persistence cathode-ray tube, and photographic recording. (b) Loudspeaker, using the beat-frequency oscillator of the receiver. The aural method was the more sensitive for detection of weak echoes.

Keying procedure : The most frequently used key. ing signals were: (a) A group of three $\frac{1}{4}$-sec. pulses (for identification of weak echoes). (b) A single pulse $\mathbf{2} \cdot 2$ sec. long (for studying short-period amplitude variations of the echo, which began to appear $2 \cdot 6$ sac. after the start of the transmitted pulss). The pulse repetition period was 6 sec.

Owing to the use of fixed aerials, observations are possible only when the moon is within the beam of the aerials, ionospheric conditions are suitable, and 'Radio Australia' is not required for broadeasting. The moon passes through the aerial beam on several successive days for two periods each month, at times related to sidereal time and hence varying with respect to solar time. The transmitters are available only during 0230-0530, 0930-1230 Eastern Australian Standard Time. In the latter period, the critical frequency of the $F_{2}$-region is usually too high for penetration to be possible. Hence the working time of the system is restricted to days when the moon is in the required part of the sky between 0230 and 0530 , that is, to about twenty days in a year.

\section{Echo Characteristics}

Observations have been made in the 0230-0530 period on thirteen days, moon echoes being received on twelve of these for an average time of forty minutes. The less suitable 0930-1230 period was used only on two magnetically disturbed days, on one of which echoes were received. 